\title{
Will Genetically Modified Foods lead us to Another Garden of Eden?
}

\author{
Wei Mingqin ${ }^{1}$ Ren Chou $^{2}$ \\ ${ }^{1,2}$ Institute of Politics and Public Management, Southwest University, Chongqing, \\ P.R.China, 400715. \\ (Email:331993982@qq.com; renchou1969@sohu.com)
}

\begin{abstract}
Biotech is called the $4^{\text {th }}$ industry revolution in human history, and the $21^{\text {st }}$ century is called the century of biotechnology represented by gene technology which trans-genetic technology is the important part of it. The biotech application speed is the quickest comparing with other technologies, and now it was regarded the best and only way to solve the global food shortage in a limited short period of time by quite many people for its application in agriculture. The estimation population in 2050 will reach to nearly 9 billions, but genetically modified foods (GMF) will really lead us to another Garden of Eden? Who should take more responsibilities for the ecosystem deteriorating conditions we are facing now? What the biodiversity sharply declining means to us? Is the life patent reasonable? By revaluation the anthropocentrism being abandoned for quite long, the answers for above questions may be sorted out.
\end{abstract}

Keywords: GMF, anthropocentrism, Food Chain, life patent, biodiversity

\section{Introduction}

Genetically modified food has aroused the hot discussing on the safety of it to us since first GMF falvr savr tomatoes were put on American consumers' dinning table in 1994, within 20 years, by ISAAA2011's statistics, the genetically modified crops planting occupies 1.6 billions hectares in 2011, it was 94 times comparing in 1996.The application speed of biotech in our food industry is astonishingly quick, but the research for the influences GMC will bring to us and environments also the rights conflicting brought by the commercialization of GMF has just started, more essays on GMF are from the food industry or agriculture fields, few essays are analyzing the GMF in a philosophical view.

\section{The Garden of Eden, GMF Pushers Sketched}

\subsection{What is Gene Modified Food?}

Genetically modified food is: To separate a target fragment of the gene sequence from one organism and insert it to another (this can be within one specie and can be in different species) organism's target position in its gene sequence by using the modern biotechnology to change the biological hereditary traits of a certain organism to make it change in shape, nutritional quality and other consumption qualities as the targets people expected, the foods directly from transgenic organism or based on the reprocessing of the raw materials from transgenic organism are called gene modified foods. So far the transgenic organism including animals and plants, but the most controversial issue is the gene modified crops for human's food industry, these include: corns, soybeans, wheat, rice and other vegetables, now many of our regular diet foods including transgenic ingredients, these includes cooking oils, many kinds of sweets, crackers, soft drinks, though the total transgenic foods proportion occupies a small ratio comparing with the traditional foods, the spreading speed of it is still surprisingly quick.

\subsection{Different Views for the Development of GMF}

Concerning the GMF issue, different scientists have different views for the potential dangers it may bring to us and our environment, at present, there are two opposite groups: "one group represented by some Chinese scientists including Jia Shirong, Zhuzhen, Chen Zhangliang, Zhang Qifa and non Chinese scientists Anthony J.Conner,Travis R.Glare,Jan-Peter Nap they maintain that there are no more dangers the GM crops will bring to us and the en- 
vironment than the normal crops,so we should be more active in promoting the genetically modified crops; The other group mainly are the biologists represented by Jan Husby,Terje Traavik,Philip J.Dale and some Chinese scientists represented by Lu Baorong, Qian Yingqian,Wei Wei,Zeng Beiwei ect they insist that there are potential dangers GMC could bring to us and also the environment which obviously we can't ignore, so we need to be more cautious in promoting the GMC. So far the scientists have not yet reached an affirmative conclusion on environmental risks of genetically modified crops."[1]

\subsection{Developing Conditions of GMF}

Biotech's application in reality represented by GMF, the commercialized speed of it is the fastest among all the high technologies after their appearance. Because some people are trying to convince the rest of us that GMF will lead us to another reachable Garden of Eden. In 1994,when the public have not known much about the GMF not even to say the knowing for its safety the first GMF, flavr savr tomato was already put into our food market, within 20 years We are on the road of GMF commercialization with a really fast speed, according to the statistics by ISAAA's "Global Status of Commercialized Biotech/GM Crops: 2011","The most compelling testimony to biotech crops is that, in the period 1996 to 2011, millions of farmers in 29 countries worldwide, made more than 100 million independent decisions to plant and replant an accumulated hectare of 1.25 billion hectares - one principal reason underpins the trust and confidence of risk-averse farmers in the technology - biotech crops deliver sustainable and substantial, socioeconomic and environmental benefits." [2] GMF is explained the best way to take us out the difficulties of the limitations of the natural resources and keep increasing populations on this planet, the population on earth in 2011 has reached 7 billions, this number will reach to 8.5 billions in 2050 by estimation, the most population increasing contributions are from developing countries, poverty and famine are popularly existing in these countries, genetically modified foods are regarded the best way so far to solve the world wide food shortage problems.

\section{The New Difficulties GMF brings}

\subsection{Safety of the GMF}

The genetically modified foods have to go through a strict safety assessment process for our body health before they are put on our table, but even so there are still quite many examples of people get allergic to the GMF foods, and this biotech application is new to us, how long this safety assessment needs is proper to give a "it is safe for us" comment we don't know, the complexity and uncertainty of GMF goes into our body still needs a lot of studies, as Rober Paarlberg said: "Judging the 'safety' of food is hardly an exact science. Through experimental testing it is possible to certify that some foods will be dangerous for human consumption, but certifying a complete absence of danger is (like any effort to prove a negative) beyond the capability of experimental science."'[3] So no organization can guarantee the $100 \%$ safety of the GMF to our body health yet.

\subsection{Biodiversity Influences}

We have realized the significance of the biodiversity to our human's own development. But the extinction speed of the living species is still belong our imagination, "Now there are about 40 millions different plants and animal species, In the different period of history before there used to be 5-40 billions different species, that is to say, only $1 \%$ survived, $99.9 \%$ species extinct."[4] Also according to the Living Planet Report 2012 by World Wild Life Fund (WWF), in the past 40 years, the vitality of the earth decreased $28 \%, 61 \%$ decreasing in tropical low income countries, our planet now is in a "very unhealthy condition." By present consuming mode, we will need 2.9 earths to sustain our population in 2050. [5] The important sign of the vitality of the earth is the biodiversity, now we have many species extinct or become endangered species. We can not ignore the important influences GM crops will bring to the existing plants, the well-known Mexican Maize germplasm pollution incident is just one case. The genetically modified crops are the targets crops specially designed for human purposes, many of them have been conducted crossing species, it means nature will not produce these plants, it is different with the natural hybridization. But these gene modified plants their pollens can flow and pollute the congeneric species or related species, this will bring the gene pollution in ecosystem. What this will bring to the non-target organism in 
nature, we have seen the hazards, but can't judge the hazard level yet, as this also needs time to assess.

\subsection{Life Patents}

"Patent on life, except the similar features with other patents, the most prominent feature of patent on life is 'maker'. Maker is a biological term, it refers to a piece of DNA sequence which related with the control of a particular expressing character, so far we haven't found all the relations of each sequence of the DNA with the expressing character. Generally speaking, 'maker' is the guide board on the road, by it we can easily found our destinations.......According to the sociology of science and also the theory of patent law, no patent will be granted to a founding existing in this nature, same as the three laws of motion found by Newton can't be granted a patent, it belongs to all of our human beings." [6] Something similar here on life patent, we are granting patents on life by the finding of the "makers", to protect the interests of some interest groups, This directly brings the new "life enclosure Movement" and intensifies the competitive plundering of the natural living organism. We should intensify the discussing of the international standard of the limitations for patents on life granting, some developed countries are applying the patent law of their countries to claims the global rights, specially represented by patents on life. Many developing countries don't have patents on life at all, but their natural resources are taken and developed rights based on the those resources are benefiting other people. Also there are conflicting of laws existing, as all the spectacular living organism in country A belongs to the people of that country A, but they are taken away and developed by people in another country B, then the other people in country B are granted patent rights according to the relative law in country $\mathrm{B}$ then their people are protected and even they claim rights to the people in country A by it, here fairness and justice are absent. Biotechnology same as other technologies, the ultimate goodness of public should be its pursuit, because all technologies are the products of human's civilizations.

\section{Justification for Anthropocentrism}

\subsection{Food chain, the Revaluation of Our Po- sition in It}

Quite many of us thinks we are on the top of the biological food pyramid, though we understand it is more reasonable to be a circle, but it is so evidently that the population expanding speed of us is so extraordinarily quick, by the homonid fossils found, the earliest pithecanthropus erectus know so far dated back 4 millions years ago, now we have over 7 million populations and we are actively participating in the evolution of nature and ourselves. We could create all the possibilities to make us survive and develop, W.H.Murdey expressed that:" By the comparison of the abilities of human beings and the limited abilities of other organism in influencing the outside environments, our abilities are continuously shown in evolution process, it makes us to be able to change the environments to adapt to our needs, that is the simple reason we can get biological success also face the biological problems, it can also promote the value of ourselves. Human beings have higher value than others in this nature, actually is the view Murdey tried to explain in his modern anthropocentrism. " [7] revaluate the position we are on the food chain is necessary and important, biologically we are only one participant on the food chain, same as other organism, the ultimate goodness for each species is survive, as Darwin once said in year 1859 "One of the most remarkable features in our domesticated races is that we see in them adaptation, not indeed to the animal's or plant's own good, but to man's use or fancy." [8] But the distinction of human beings and other living organism is the reason we have, as Pico della Mirandola said: "we were put in the middle of heaven and earth". [9] that is the reason we could have the immortal soul while we have the mortal body. That is the value of our existing, we can manipulate the nature by GMO, under the situation of with present limited sources and keeping increasing populations 80 million more each year, the ultimate aim we agreed is: survive, for our species. It is not a shame thing to say so, as nature has its own law, by the reason we owned we can tell that and by abiding by the natural law we strongly survived till now.

\subsection{Revaluation of "Anthropocentrism"}

Anthropocentrism used to be as a negative word in the eyes of the environmentalists and environmental ethicists because it asserts that, the interest of human is the value measure of everything, there are only obligations between 
human themselves, nature only supplies tool function for these obligations. But nonanthropocentrism, in other words, Ecocentrism asserts to build up a value assessment system based on the nature itself, it severely criticized the anthropocentrism. Factually, there is no strictly opposition between anthropocentrism and non-anthropocentrism, because the interactions of nature and human is obvious and no one denies that, anthropocentrism and nonanthropocentrism they are in two different dimensions, anthropocentrism and ecocentrism can be harmonized into together, focused on human being, this special uniquely exist, a reason being. Surviving and developing is the natural desire of us, we can't ask other beings to bear the responsibilities for our development, and we can hardly find other being like us in the food chain so far can exert such big influences as us to nature.

\subsection{Human Beings: a Unique Reason Being}

Immanuel Kant stood in awe for two things in his life: the starry sky above and moral law inside, We can always make changes of ourselves to adapt to nature or change the environments to adapt to our needs, the distinction makes us unique in this ecosystem is we are the "reason beings". We know the limitations and we used to do things under a limit that is we can't break the natural law nature sets. If we do not, we will be punished and then we learn and we control ourselves. But with the further technology development, we starts to reveal part of the secrets of life and we eager to use them to make our life better, nothing wrong with that, the thing is we need to know the proper limits nature sets so our technique 's application will not bring us hazards. The reason we owe is making us distinctive with the rest beings.

\section{Priority of GMF and Biodiversity}

\subsection{Species Barriers}

Gene modification technology, the typical feature of it is: it crossed the species barrier, species barriers that is the base all species could own a sustainable and stable development. Each specie has been through a process that: by millions years of struggling to survive and live better battle, we owe the present dynamic biological balance. Each species are influencing each other in this biosphere. The thing is there has never been one kind of specie can influence the rest all species as we human beings. Because by the 4 million years of evolution, our human beings we have reached such a civilization level by the accumulations of the knowledge we learned from nature by the efforts from generations to generations. We are still on the way of learning from nature. During this process we have had many lessons before, we tried to manipulate nature and we have bad lessons, but we have never been experienced what are doing now, we found a very few part of the secret of the life code, the secret of the genes. We have been always asking ourselves: where we are from and where we are going? And what we can do? We are not satisfied with being hardly struggling to survive with the safe but conventional agriculture, because we believe by the deciphering of the even still very few part of life code: gene, we can create our own Garden of Eden that is where we are heading for. "When genetic engineers disregard the productive boundaries set in place by natural law, they run the risk of destroying our genetic encyclopedia, compromising the richness of our natural biodiversity and creating 'genetic soup.' What this means to the future of our ecosystem, no one knows." [10]

\subsection{Food Shortage}

The population on earth now has exceeded 7 billions, the number will be 8.5 billions in 2050 , the number of people in famine is 1 billion now, and GMF is regarded one of the best ways to solve the food shortage crisis on this planet. Conventional agriculture has helped us till today, because the great profits competition behind the transgenic technology, conventional agriculture now is said can't afford to support us anymore, the potentiality of it has come to the end. It is not rational to deny the help of the techniques used in conventional agriculture, without them, our populations can hardly reach to the number as now. Because of the attention on GMF, fewer investments and attentions are put in conventional agriculture. Contrarily, natural organic foods produced by conventional agriculture are welcome by the public, they are the foods we have eaten millions of years, and they have good markets that should be the direction of conventional agriculture, organic foods yield by conventional agriculture. 
More or less we have to admit, driven by the capital interest, we are pushed to commercialize GMF in a rapid speed not caring enough the more passive situation we may be lead to by it. By the appeal by director-general of UNFAO Diouf: emergency action needed for the security of the world food," Today, the fact is: the assistance to the agriculture dropped from 8 billion USD from 1984(based on 2004 standard) to 3.4 billion USD in 2004, the factual decreasing rate is $58 \%$. The percentage of official developing assistance of agriculture dropped from $17 \%$ in 1980 to $3 \%$ in 2006 , the resources allocated by international and regional financial institutions for agricultural activities reduced sharply while agriculture is the main support for the $70 \%$ poor people." [11] One of the ultimate aims of GMF commercialization is said to help to eradicate the poverty and hunger, the more proper to do may be: remember the barriers and respect the law nature sets, this should be the bottom line or our morals, Fully use the knowledge we learned in the struggles of the surviving in this nature, all the scientific practices should be taken in a greater caution, because we used to allow the errors happen in scientific experiments and practices, but we rarely allow the errors happen in big projects----once the GMF are massively spread in nature, this action can be called the project, because we rarely can bear the bad consequences of a project. What's more, only someone are benefit from the profits of GMF, when environments hazards caused by it happened, all the living organism will have to bear the catastrophic consequences of it. That consequence nobody can afford, the injustice in it is, we including other living beings all will have to face that fate together.

\subsection{Biodiversity and patents on life}

We have realized the significance of the close bond of biodiversity to our own developing. According to the Living Planet Report 2012 by World Wild Life Fund(WWF), "in the past 40 years, the vitality of the earth decreased $28 \%, 61 \%$ decreasing in tropical low income countries, our planet now is in a 'very unhealthy condition.' By present consuming mode, we will need 2.9 earths to sustain our population in 2050."[12]The important sign of the vitality of the earth is the biodiversity, now we have many species extinct or become endangered species. By the commercialization of the GMF, by the patents granting on life in some countries, this will deteriorate the biodiversity disappearing. "By the Convention on Biological Diversity of UN, biological resources and gene resources are within the national sovereignty, there is no doubts they need protection, but how there is no consensus for it." [13] The intervention of transgenic technology development world wide, the demanding for the various wild living resources and the economical developing imbalance is increasing the difficulty for the protection of the biodiversity. The biodiversity protecting conditions in developing countries should seriously be paid more attention, the relative rights of the particular biological resources in the developing countries should be considered in the global development of biotechnology. Life patents registering activities in some countries have violated the other countries sovereign rights, the rights conflicts need more international negotiations to solve. Before that, the developing countries should put the wild species protection to a level high enough, the well conservation of the wild species, specially the plants has significant meanings for the well protection of the ecosystem.

\section{Conclusion}

GMF as the representative achievement of human success in the frontier biotech, specifically in gene technology, the commercialization of it should be in great caution. The global population reached to 7 billions till 2011, this enhances the strong appeal for solving the problem of the food shortage with the decreasing limited sources around the world in shortterm, but the commercialization of the GMF need to be put into effect considerately rather than hastily. To promote the public's awareness of the potential dangers which transgenic technology will bring about to the nature is the indispensable mission of science. Being one participant in food chain of this biosphere, by owing the reason character, human beings should undertake the responsibility in nature protection. Anthropocentrism does not emphasize the value of human beings are higher than the rest living beings; it indicates more responsibilities on human beings. Biotech is a sharp sword, how to play it well, the premise is: By the balance of moral law and natural law 
guided by reason, the ultimate good life can be approached.

\section{References}

[1] LU Qun-feng, Xiao Xian-jing, A Summary on the Debates of Environmental Risks of Genetically Modified Crops[J].Journal of Shandong University of Science and Technology, Social Sciences, Vol.11 No. 5,Oct,2009.

[2] Clive James, Global Status of Commercialized Biotech/GM Crops: 2011, http://www.isaaa.org/resources/publicati ons/briefs/43/highlights/default.asp

[3] Nina V. Fedoroff and Nancy Marie Brown, Mendel in the Kitchen, a scientist's view of Genetically Modified Foods, Joseph Henry Press Washington,D.C.,2004,Page155.

[4] Leften Stavros Stavrianos, A Global History, the $7^{\text {th }}$ Edition, Peking University Press, Book I(total two books),Jan,2005(in Chinese).

[5] Web of Environment China: http://www..com.cn/xwzx/hq/qt/20120 5/t20120521_717776.html (In Chinese).

[6] Chen Mingren, Patent on Life,A New "Enclosure Movement", edited by Mengyan,WTO World, Patent on Life, http://www.jssti.com.cn(In Chinese).

[7] Susan J.Armstrong, Rechard G, Botzler, Chief Editor: Environment Ethics: Divergence and Convergence, MacgrawHill Inc.,1993,page:302-309,translated by Zhang Jiangang (in Chinese)

[8] Same as above [3], Page 1.

[9] Pico della Mirandola, On the Dignity of Man, Chinese version translated by $\mathrm{Gu}$ Chaoyi and Fan Honggu, Peking University Press,Sep,2010.Page17.

[10] Same as above [3], p72.

[11]Director-general of UNFAO Jacques Diouf----emergency action for security of world food, Food Decision Consultation, Vol11,2008,(In Chinese).

[12] Same as above [6].

[13] Same as [12]. 